\title{
A Meta-Analysis for the Impact of Transgenic Crop Adoption on Com and Soybean Yield
}

\author{
Sang-Hoon Lee*, Gyeong-Bo Lee, Seon-Woong Hwang, Hye-Jin Kim', and Doug-Young Chung ${ }^{1}$ \\ Dept. of Rice and Winter Cereal Crop, NICS RDA, Iksan Korea 570-080 \\ ${ }^{I}$ Dept. of Bio-Environmental Chemistry, College of Agriculture and Life Sciences, Chungnam National University, \\ Daejeon Korea 305-764
}

\begin{abstract}
Although there is a broad dispute over genetically modified foods on safety, the worldwide adoption of transgenic crops is rapidly increasing. The objectives of this study were to identify trends in the effects of transgenic on crop yields and examine the effect of agricultural variables including crop type, biotech trait, tillage system, and yield environment on com and soybean yield. A meta-analysis from the 34 peer-reviewed scientific literatures was conducted to compare the crop yield between transgenic crops and conventional varieties. Results showed that the yield of transgenic com and soybean was strongly dependent on growing conditions. Transgenic hybrids had higher yield potential in the low crop yield environments such as high weeds and/or insect infestation, low soil water, and cool temperature conditions, while transgenic crops did not have yield advantages in high yield environments. The results from this study suggest that producers should consider the potential yield environmental conditions and possible yield reductions when producers choose crop hybrids in their fields.
\end{abstract}

Key words: Transgenic crop, Corn, Soybean, Yield, Meta-analysis

\section{Introduction}

World population is expected to grow to approximately 9.3 billion people by 2050, up 30\% from 7 billion in 2011 (UN, 2012). Almost all these growth will take place in developing countries, where a population of 5.6 billion is expected to increase to 7.9 billion by 2050 . As the world population grows and family income rises, so will the demand for food. Therefore, crop production must increase to meet the demand of the world population in the next few decades. The yields of corn and soybean, two major crops in the world, continue to increase due to the improved management practices and traditional breeding programs (Gurian-Sherman, 2009). Adoption of transgenic crops (TCs) may offer many opportunities to help increase crop yields and provide environmental benefits such as reduced erosion and runoff and reduced greenhouse gas emissions by conservation of soil organic carbon (Triplett Jr. and Dick, 2008). Although Korea did not allow adopting

\footnotetext{
Received : 2012. 7. 20 Accepted : 2012. 8. 3

*Corresponding author : Phone: +82428216739

E-mail: dychung@cnu.ac.kr
}

TCs, the adoption of TCs in the world rapidly increased. For instance, the adoption of transgenic soybeans dramatically increased after their introduction, and approximately 47 percent (74.5 million ha) of the soybeans in the world are transgenic, and almost $90 \%$ of principal TCs are transgenic in the US (James, 2012).

Weeds and insects are major sources of yield losses for agricultural crops worldwide. Transgenic crops with glyphosate/glufosinate resistant (GR) and/or insect resistant (IR) traits could increase crop yields by minimizing yield losses from insects and weeds competition. However, the primary impact of TCs up until now has been to provide more cost effective and easier management, not necessarily yield gains (Fernandez-Cornejo and Caswell, 2006). Weed and insect control in conventional varieties is particularly difficult due to the narrow window allowing for herbicide/insecticide spraying. Transgenic crops, especially in developing countries, where effective weed and insect control is often limited, will be an effective way to increase crop yield.

Several studies have conducted yield comparisons between GR hybrids and conventional varieties. Brookes 
(2003) observed that an average $31 \%$ yield increase has been shown by the adoption of GR soybean in Romania. However, yield potential of GR soybean hybrids has been questioned in other instances (Bertram and Pedersen, 2004; Elmore et al., 2001; Oplinger et al., 1998; Thomas et al., 2007). For instance, Bertram and Pedersen (2004) found that no yield difference between transgenic and conventional soybean varieties was observed in low yield environments caused by cool weather conditions, but transgenic soybean averaged 6\% less yield than conventional varieties in a high yield environment. This result agrees with other studies (Burke et al., 2008; Ferrell and Witt, 2002).

Insect resistant corn with Bacillus thuringiensis $(\mathrm{Bt})$ was introduced in 1996 and many survey and field studies supported that IR corn results in increasing corn yield. For example, a survey of US producers showed that IR corn had $840 \mathrm{~kg}$ per hectare higher corn yield compared to conventional corn yield (Fernandez-Cornejo and Li, 2005). Marra et al., (2002) also observed that IR corn significantly increased yield across the Corn Belt the majority of years. It is generally recognized that the use of IR corn for European corn borer (ECB, Ostrinia nubilalis) control results in average yield increases of 5-10 percent, although the yield increase is dependent upon year and regional variations (Gomez-Barbero et al., 2008b).

Adoption of TCs was shown to help to reduce yield loss due to weeds and insects, thus increasing the profits of producers by cost savings. Yield benefits which come from the use of TCs were most pronounced in locations and years in which weeds and insects infestations were high (Brookes and Barfoot, 2009). Brookes and Barfoot (2009) investigated the global socio-economic and environmental impacts of TCs occurring between 1996 and 2007. When compared to conventional varieties, the utilization of transgenic soybeans and corn in 2007 created $6.5 \%$ and $1.9 \%$ higher production levels, respectively. Global farm level income benefits derived from adopting GR crops versus conventional varieties was $\$ 2.76$ billion for soybean and $\$ 442$ million for corn in 2007. Among them, 95\% was due to cost savings and $5 \%$ was due to yield gains by improving weed control. The global impact of using IR corn was $\$ 1.52$ billion in 2007 and most of this gain was derived from improved crop yields in most countries when compared to average yields derived from a conventional crop hybrid. These results support the theory that profitability increases through higher yields and lower input costs, positively influencing the adoption of transgenic soybeans and corns.

Although extensive studies have investigated yield impacts of transgenic corn and soybean with spatial and temporal variations, results have shown the positive, no-effect, or even negative effects on crop yield, these contrasting results demonstrate the need for a comprehensive quantitative review of the effect of transgenic adoption on crop yield. The objectives of this study were to: 1) summarize and identify trends in the effects of transgenic corn and soybean in yield from the peer-reviewed papers; and 2) examine the effect of variables (such as crop type, biotech trait, tillage system, and yield environment) on crop yield under different years and locations.

\section{Material and Methods}

Multi-database searches (AGRICOLA (CSA), CAB Abstracts (Ovid), CSA Illumina, Web of Science (ISI), EBSCO MegaFile (EBSCO), etc) were used to identify literatures on transgenic crop impacts on corn and soybean yields. Studies were selected for inclusion in the data set if the following criteria were met; 1) studies measured the effect of transgenic corn and soybean with GR and/or IR trait; and 2) the study included comparisons between transgenic and non-transgenic (nearisoline) varieties under the same growing conditions.

Application of these criteria yielded data from a collection of 34 suitable peer-reviewed publications. The transgenic traits used in these studies include those intended for use primarily in GR soybean and corn, and IR corn. Applying these criteria, combined with several studies reporting multiple independent experiments or measurements of different years and locations, yielded a total of 450 independent observations of the effects of the adoption of TCs compared to conventional varieties.

Each observation was calculated as a response ratio (yield of transgenic hybrid/yield of conventional nontransgenic variety). The categorical variables which could influence the response variable were: 1) transgenic traits [glyphosate/glufosinate resistant (GR), insect resistant (IR), and stacked trait (GR+IR)], 2) crop types (corn and soybean), 3) tillage systems [no-tillage (NT) and tillage system (T)], and 4) crop yield environment 
[high yield environment (HYE) and low yield environment (LYE)]. Low yield environment was considered when crop yield was influenced by low water in soil, cool temperature, or had a high infestation of weeds or insects. High yield environment was considered as the maximum yield condition with given information.

\section{Results and Discussion}

The studies used for the yield comparison between transgenic and conventional varieties are summarized in Table 1. The majority of the studies originated from the United States due to its high adoption rate. When all studies (34 studies in 450 observations) were combined, the mean yield of TCs was $4.5 \%$ higher (7,560 vs 7,231 $\mathrm{kg} \mathrm{ha}^{-1}$ ) compared to non-transgenic crops, but there was no statistical significance on yield difference. Crop yields used in this study have very wide ranges due to the variations in growing conditions and yield potential of selected hybrids pairs (Fig. 1).

Table 1. Studies used in this analysis.

\begin{tabular}{|c|c|c|c|c|}
\hline Reference & Crop & Trait & Location & Year \\
\hline Barry et al., 2000 & Corn & IR & $\mathrm{MO}, \mathrm{USA}$ & 1996 \\
\hline Bertram and Pedersen, 2004 & Soybean & GR & WI, USA & 1997-1999 \\
\hline Bruns and Abbas, 2006 & Corn & IR & MS, USA & 2002-2004 \\
\hline Buntin et al., 2004 & Corn & IR & GA, USA & $1999-2000$ \\
\hline Buntin, 2008 & Corn & IR & GA, USA & 2006-2007 \\
\hline Burke et al., 2008 & Corn & GR & $\mathrm{NC}, \mathrm{USA}$ & 2003 \\
\hline Catangui, 2003 & Corn & IR & $\mathrm{SD}, \mathrm{USA}$ & 1997-1999 \\
\hline Catangui and Berg, 2002 & Corn & IR & $\mathrm{SD}, \mathrm{USA}$ & 1997-1999 \\
\hline Chilcutt et al., 2006 & Corn & IR & TX, USA & $1999-2000$ \\
\hline Cox and Cherney, 2001 & Corn & IR & NY, USA & 1997-1999 \\
\hline Cox et al., 2009 & Corn & GR+IR & NY, USA & $2007-2008$ \\
\hline Dalmacio et al., 2007 & Corn & IR & Philippines & 2003-2004 \\
\hline Dillehay et al., 2004 & Corn & IR & PA, USA & $2000-2002$ \\
\hline Elmore et al., 2001 & Soybean & GR & NE, USA & 1998-1999 \\
\hline Folmer et al., 2002 & Corn & IR & NE, USA & 1998 \\
\hline Heatherly et al., 2002 & Soybean & GR & MS, USA & 1996-1999 \\
\hline Heatherly et al., 2003 & Soybean & GR & MS, USA & 1999-2001 \\
\hline Heatherly et al., 2005 & Soybean & GR & MS, USA & $2000-2003$ \\
\hline Lauer and Wedberg, 1999 & Corn & IR & WI, USA & 1995 \\
\hline Loecker et al., 2010 & Soybean & GR & KS, USA & 2006-2008 \\
\hline Ma et al., 2009 & Corn & IR & Canada & 2003-2005 \\
\hline Ma and Subedi, 2005 & Corn & IR & Canada & $2000-2002$ \\
\hline Macrae et al., 2005 & Soybean & IR & MS, AL, GA, LO, USA & 1996-1997 \\
\hline Magg et al., 2001 & Corn & IR & Germany & 1998-1999 \\
\hline McPherson and Macrae., 2009 & Soybean & IR & GA, USA & 2003-2007 \\
\hline Mungai et al., 2005 & Corn & IR & MO, USA & $2002-2003$ \\
\hline Nelson and Renner, 2001 & Soybean & GR & MI, USA & $1997-1998$ \\
\hline Pilcher and Rice, 2003 & Corn & IR & IA, USA & 1996-2008 \\
\hline Shaw et al., 2001 & Soybean & GR & MS, USA & 1997 \\
\hline Singer et al., 2000 & Corn & IR & NJ, USA & $1997-1998$ \\
\hline Singer et al., 2003 & Corn & IR & DE, USA & $2000-2001$ \\
\hline Stanger and Lauer, 2006 & Corn & IR & WI, USA & 2002-2004 \\
\hline Subedi and Ma, 2007 & Corn & IR & Canada & 2003-2004 \\
\hline Traore et al., 2000 & Corn & IR & IA, USA & $1997-1998$ \\
\hline
\end{tabular}




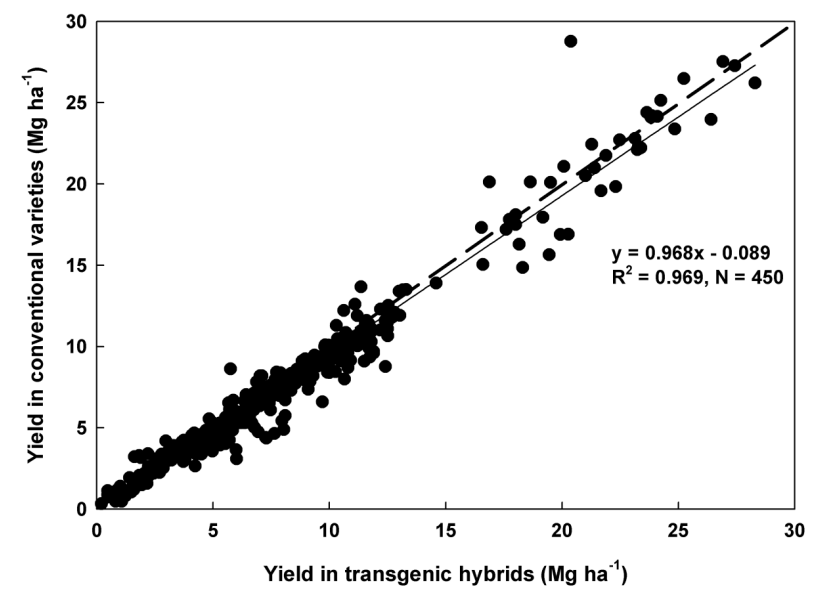

Fig. 1. Linear regression of com and soybean yield between transgenic hybrids and its counter-part conventional varieties when all studies (34 studies in 450 observations) were combined. The dashed line represents $y=x$ and the solid line shows a regression line.

In the early adoption stage of TCs, transgenic crops with IR traits usually yielded similar to near-isolines (Baute et al., 2002; Cox and Cherney, 2001; Dillehay et al., 2004; Traore et al., 2000), suggesting that the insertion of an IR gene in the early IR crops did not provide higher yield. However, some of the first transgenic crops with GR traits provide the same or even lower yield on average than conventional varieties due to the introduction of the GR gene into varieties with lower yield potential (Elmore et al., 2001; Heatherly et al., 2002 and 2003; Loecker et al., 2010; Shaw et al., 2001). However, transgenic traits were later introduced into improved potential yield varieties and generally showed that transgenic hybrids produced similar or higher yields than conventional varieties. Raymer and Grey (2003) showed, for instance, that transgenic soybeans yielded $260 \mathrm{~kg} \mathrm{ha}^{-1}$ less than conventional varieties in 1995 and 1996, but the yield difference between transgenic and conventional varieties was lower in the 1998 analysis. This result suggests that the average TC yield had improved with continuous introduction of high yield transgenic hybrids, probably due to the use of more elite germplasm in variety development which has improved crop yield associated with the use of transgenic trait. These introductions of transgenic hybrids eventually would improve crop yields over time.

Transgenic Traits Effect Mean grain yield of IR trait hybrids from 9 studies with 113 observations was higher $\left(9,050 \mathrm{vs} 8,580 \mathrm{~kg} \mathrm{ha}^{-1}\right)$ than non-transgenic varieties, but transgenic GR trait hybrids from 24 studies with 329 comparisons had lower grain yield (2,980 vs $3,050 \mathrm{~kg} \mathrm{ha}^{-1}$ ) compared to non-transgenic varieties. For the GR trait, the response ratio was 0.966 , with a confidence interval that did not encompass one (Fig. 2a). For GR+IR stacked trait, the response ratio was 1.024 and a $95 \%$ upper and lower confidence ratio of 0.909 and 1.138. The wide confidence interval of crops with GR+IR stacked trait was the result of the limited number of study (one) and observations (eight). For the IR trait, the response ratio was 1.084 , with a $95 \%$ confidence interval that did not encompass one. Thus, it can be inferred that the use of TCs with the IR trait yielded 8.4\% more compared to conventional varieties. In contrast, the use of TCs with the GR trait produced 2.4\% lower grain yield compared to non-transgenic varieties.

Insects infest corn ears, which causes direct loss of grain yield. However, corn with the IR trait reduce ear infestations and larval number per ear, causing less kernel damage compared to conventional varieties (Buntin et al., 2000) and therefore effectively prevents yield losses. Numerous studies have investigated yield impacts of transgenic crops with IR traits (Dillehay et al., 2004; Gomez-Barbero et al., 2008b; Stanger and Lauer, 2006). For instance, Stanger and Lauer (2006) conducted yield response to planting population studies in Wisconsin and found Bt hybrid corn yielded 5.9 to $8.0 \%$ more than their near isolines. Even though the yield increase in Bt hybrid corn was documented in many other field experiments (Bruns and Abbas, 2006; Catangui and Berg, 2002; Mungai et al., 2005; Singer et al., 2000), crop yield varied depending upon regions and years due to the different growing conditions. For example, transgenic $\mathrm{Bt}$ corn did not provide a yield increase over their normal counterparts under conditions of low corn borer infestation in the northeastern US (Cox and Cherney, 2001). As with Bt corn for corn borer, Bt corn for rootworm control did not provide an indirect yield benefit under low insect infestation conditions. No yield increase for transgenic Bt corn under low pest pressure conditions was observed in several studies (Baute et al., 2002; Catangui and Berg, 2002; Coulter et al., 2010; Sheridan, 2009; Stanger and Lauer, 2006; Traore et al., 2000).

Crop Types Effect The corn yield from 302 observations in 23 independent studies ranged from 

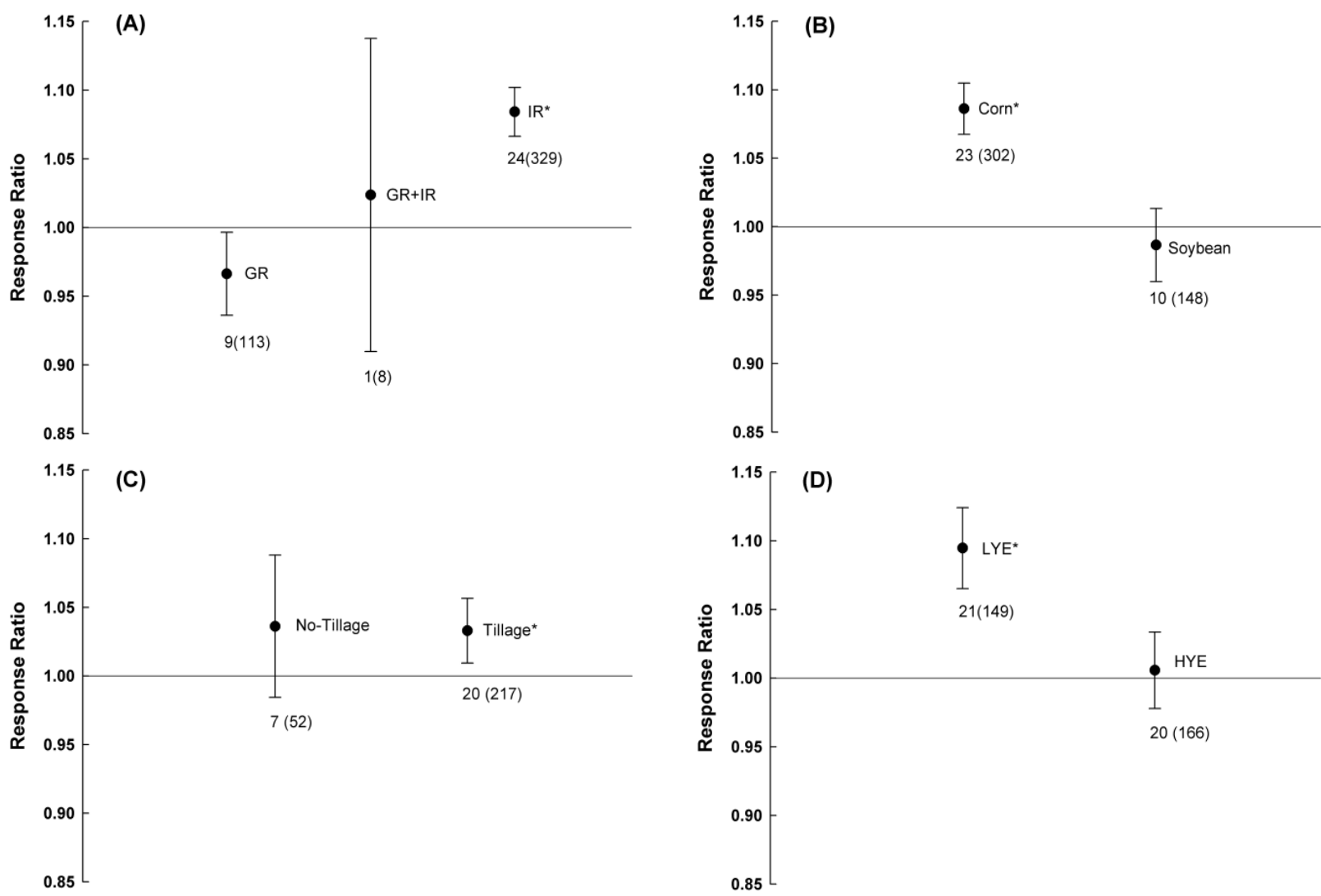

Fig. 2. Mean response ratio (yield of transgenic crop/yield of near-isoline): (A) transgenic traits [glyphosate/glufosinate resistant (GR), insect resistant (IR), and stacked trait (GR+IR)], (B) crop types (com and soybean), (C) Tillage systems (No-Tillage and Tillage), and (D) yield environmental conditions environment [high yield environment (HYE) and low yield environment (LYE)]. Emor bars represent $\mathbf{9 5 \%}$ confidence intervals. Values below each bar indicate the number of papers and, in parentheses, the number of observations used in each bar. An asterisk indicates that the $95 \% \mathrm{Cl}$ is higher than one.

1,940 to $28,300 \mathrm{~kg} \mathrm{ha}^{-1}$ for transgenic hybrids, and 1,490 to $28,770 \mathrm{~kg} \mathrm{ha}^{-1}$ for conventional corn varieties. Transgenic soybean yield ranged from 200 to $5,470 \mathrm{~kg}$ $\mathrm{ha}^{-1}$, and conventional soybean varieties ranged from 340 to $5,470 \mathrm{~kg} \mathrm{ha}^{-1}$. The mean response ratio in corn was 1.086 and the $95 \%$ confidence interval did not encompass one (Figure 2b). The mean response ratio in soybean was 0.987 , with a $95 \%$ confidence interval that did encompass one. It means that the adoption of transgenic corn produced an overall higher grain yield than conventional corn varieties, but transgenic soybean did not provide an overall yield increase compared to non-transgenic varieties on average. This result may be related to transgenic traits of the crop themselves as mentioned above. Most of the transgenic soybeans used in this studies were GR traits, with an exception of one study (Macrae et al., 2005), in contrast, transgenic corn contains various types of transgenic traits (GR, GR+IR, or IR).

Tillage Systems Effect There was no statistical significant effect of tillage system on crop yield, even though the mean yield of transgenic crops was $5.1 \%$ and $4.0 \%$ higher compared to non-transgenic varieties under the no-tillage and tillage systems, respectively (Figure 2c). The introduction of GR crops eliminated most pre-emergent herbicides that often were incorporated into the soil and instead relies on post-emergent herbicides such as glyphosate. Therefore, the shift to post-emergent herbicides may promote no-tillage practices that can provide environmental benefits (Holland, 2004; Locke, et al., 2008; Triplett Jr. and Dick, 2008). Producers already employing no-tillage systems were more likely to adopt GR hybrids than producers using a conventional tillage system, and producers adopting GR crop varieties were more likely to shift to no-tillage than producers not adopting GR crops and using tillage (Mensah, 2007; Buhler, 1992; Kapusta and Krausz, 1993). When weeds are controlled, crop yield and net return in no-tillage systems are often equivalent or greater than corresponding conventional tillage 
systems (Buhler, 1992; Kapusta and Krausz, 1993). DeFelice et al., (2006) reported that the corn and soybean yield difference between no-tillage and conventional tillage practices was found to be negligible. Although the adoption of TCs in no-tillage practices did not provide a significant yield increase, the adoption of TCs in no-tillage systems could lead to easier management practices and increased environmental benefits such as reduced soil erosion, loss of soil moisture, runoff, and reduced greenhouse gas emissions by conservation of soil organic carbon (Holland, 2004),

Yield Environments Effect Mean grain yield under LYE conditions from 21 studies in 149 independent observations was $8,170 \mathrm{~kg} \mathrm{ha}^{-1}$ for TCs and $7,640 \mathrm{~kg} \mathrm{ha}^{-1}$ for non-transgenic crops. Under LYE conditions, the mean response ratio was 1.095 , with a 95\% confidence interval that did not encompass one (Figure 2d). The mean yield from 29 studies in 116 observations under HYE conditions did not show a significant effect of TCs on yield (response ratio of 1.006). These data suggest that TCs should provide higher yield compared to conventional varieties in LYE such as water stress, low temperature, or low infestation levels of weed and/or insects. On the other hand, TCs should provide the same yield to conventional varieties when the level of yield environment is high.

Several studies on yield impacts of TCs have shown that the yield increase through the adoption of TCs was dependent on regional differences due to the regional variation in weed and insect infestations (Gomez-Barbero et al., 2008a; Singer et al., 2003). Weed and insect infestations vary from one region to another and from one year to another. Crop yield also varies depending upon these growing conditions and is determined by the effectiveness of weed and insect management. Transgenic crops can prevent yield losses by protecting the plant from certain weeds and insects compared with conventional crops, particularly when weed and insect infestations are high. Therefore, the principal benefits of TCs will not be the primary factor in increasing yield where infestation of weeds and insects are low. This was well demonstrated by several researchers. For instance, Traore et al., (2000) found that there was 9\% yield increase of transgenic hybrids over conventional varieties when ECB infestation was high, while transgenic hybrids performed similarly to conventional counterparts in the low ECB infestation conditions. These data suggest that TCs would provide the similar yield to conventional varieties when the levels of insects or weeds are low or normal. When infestation levels of insects and weeds are high, TCs would provide higher yield compared to the conventional varieties. These trends were observed by other field studies (Bertram and Pedersen, 2004; Bruns and Abbas, 2006; Dillehay et al., 2004; Heatherly et al., 2002; Heatherly et al., 2003; Lauer and Wedberg, 1999; Mungai et al., 2005; Shaw et al., 2001; Singer et al., 2000; Stanger and Lauer, 2006).

Soybean yield comparisons between GR hybrids and conventional varieties have also shown that soybean yield were dependent on growing conditions (Bertram and Pedersen, 2004; Elmore et al., 2001; Fernandez-Cornejo et al., 2002; Heatherly et al., 2002; Heatherly et al., 2003; Shaw et al., 2001). For instance, Bertram and Pedersen (2004) found that no yield difference between transgenic and conventional soybean variety was observed in LYE caused by cool weather conditions, but transgenic soybean averaged $6 \%$ less yield than conventional varieties in normal temperature conditions. A field study also showed that GR soybean produced greater yield and net returns in LYE by drought stress, but conventional varieties generally produced greater yield and net return than transgenic soybeans in irrigated environment (Heatherly et al., 2002; Heatherly et al., 2003). The results are speculated that current conventional varieties have been bred to have high yield potentials under low to moderate infestation because of their great tolerance to infestation damage. Therefore, when it is certain that weed and/or insect infestation will be above the economic threshold, the use of transgenic hybrids may provide increased yield (and a cost benefit) compared to conventional varieties in a low yield environment.

\section{Summary}

This study analyzed 34 papers, with 450 observations, on transgenic crop yield and showed that the yield of transgenic corn and soybean with GR and/or IR traits was strongly dependent on growing conditions. Transgenic hybrids had higher yield potential in the low crop yield environments such as high weeds and/or insect infestation, low soil water, and cool weather conditions. On the other hand, transgenic crops did not have higher yield potentials compared to conventional 
varieties in high yield environments. Results from this study suggest that when producers choose crop hybrids, producers must consider the potential yield environmental conditions and possible yield reductions in each field, although crop yield is more strongly influenced by growing conditions, management practices, and weather variations compared to the crop varieties.

\section{REFERENCES}

Barry, B.D., L.L. Darrah, D.L. Huckla, A.Q. Antonio, G.S. Smith, and M.H. O'Day. 2000. Performance of transgenic corn hybrids in Missouri for insect control and yield. J. Econ. Entomol. 93:993-999.

Baute, T.S., M.K. Sears, and A.W. Schaafsma. 2002. Use of transgenic Bacillus thuringiensis Berliner corn hybrids to determine the direct economic impact of the European corn borer (Lepidoptera: Crambidae) on field corn in eastern Canada. J. Econ. Entomol. 95:57-64.

Bertram, M.G., and P. Pedersen. 2004. Adjusting management practices using glyphosate-resistant soybean cultivars. Agron. J. 96:462-468

Bonny, S. 2007. Genetically modified glyphosate-tolerant soybean in the USA: Adoption factors, impacts and prospects. A review. Agron. Sustain. Dev. 28:1-11.

Brookes, G. 2003. The farm level impact of using Roundup Ready soybeans in Romania. Brookes West, Canterbury, Kent, UK.

Brookes, G., and P. Barfoot. 2009. GM crops: Global socioeconomic and environmental impacts 1996-2007. Available at http://www.pgeconomics.co.uk/pdf/2009globalimpactstudy. pdf. Dorchester, UK.

Bruns, H., and H.K. Abbas. 2006. Planting date effects on Bt and non-Bt corn in the mid-south USA. Agron. J. 98:100-106.

Buhler, D.D. 1992. Population dynamics and control of annual weeds in corn (Zea mays) as influenced by tillage systems. Weed Sci. 40:241-248.

Buntin, G.D. 2008. Corn expressing cry $1 \mathrm{AB}$ or cry $1 \mathrm{~F}$ endotoxin for fall armyworm and corn earworm (Lepodoptera: Noctuidae) management in field corn for grain production. Fla. Entomol. 91:523-530.

Buntin, G.D., J.N. All, R.D. Lee, and D.M. Wilson. 2004. Plant-Incorporated Bacillus thuringiensis Resistance for control of fall armyworm and corn earworm (Lepodoptera: Noctuidae) in corn. J. Econ. Entomol. 97:1603-1611.

Buntin, G.D., R.D. Lee, D.M. Wilson, and R.M. McPherson. 2000. Evaluation of yieldgard transgenic resistance for control of fall armyworm and corn earworm (Lepidoptera: Noctuidae) on corn. Fla. Entomol. 84:37-42.

Burke, I.C., W.E. Thomas, J.R. Allen, J. Collins, and J.W. Wilcut. 2008. A comparison of weed control in herbicideresistant, herbicide-tolerant, and conventional corn. Weed Technol. 22:571-579.

Catangui, M.A. 2003. Transgenic Bacillus Thuringiensis corn hybrid performance against univoltine ecotype European corn borer (Lepidoptera: Crambidae) in South Dakota. J. Econ. Entomol. 96:957-968.

Catangui, M.A., and R.K. Berg. 2002. Comparison of Bacillus thuringiensis corn hybrids and insecticide-treated isolines exposed to bivoltine European corn borer (Lepidoptera: Crambidae) in South Dakota. J. Econ. Entomol. 95:155-166.

Chilcutt, C.F., G.N. Odvody, J.C. Correa, J. Remmers, and R.D. Parker. 2006. Decreased Whorl and Ear Damage in Nine Mon810 Bacillus thuringiensis (Bt) transgenic corn hybrids compared with their non-Bt counterparts. J. Econ. Entomol. 99: 2164-2170.

Coulter, J.A., E.D. Nafziger, M.R. Janssen, and P. Pedersen. 2010. Response of Bt and near-isoline corn hybrids to plant density. Agron. J. 102:103-111.

Cox, W.J., and D.J.R. Cherney. 2001. Influence of brown midrib, leafy, and transgenic hybrids on corn forage production. Agron. J. 93:790-796.

Cox, W.J., J. Hanchar, and E. Shields. 2009. Stacked corn hybrids show inconsistent yield and economic responses in New York. Agron. J. 101:1530-1537.

Dalmacio, S.C., T.R. Lugod, E.M. Serrano, and G.P. Munkvold. 2007. Reduced incidence of bacterial rot on transgenic insect-resistant maize in the Philippines. Plant Dis. 91:346-351.

DeFelice, M.S., P.R. Carter, and S.B. Mitchell. 2006. Influence of tillage on corn and soybean yield in the United States and Canada. Available at www.plantmanagementnetwork.org.

Dillehay, B.L., G.W. Roth, D.D. Calvin, R.J. Kratochvil, G.A. Kuldau, and J.A. Hyde. 2004. Performance of Bt corn hybrids, their near isolines, and leading corn hybrids in Pennsylvania and Maryland. Agron. J. 96:818-824.

Elmore, R.W., F.W. Roeth, L.A. Nelson, C.A. Shapiro, R.N. Klein, S.Z. Knezevic, and A. Martin. 2001. Glyphosate-resistant soybean cultivar yields compared with sister lines. Agron. J. 93:408-412

Fernandez-Cornejo, J., C. Alexander, and R.E. Goodhue. 2002. Dynamic diffusion with disadoption: The case of crop biotechnology in the USA. Agri. Resour. Econo. Rev. 31:112-126.

Fernandez-Cornejo, J., and M. Caswell. 2006. The first decade of genetically engineered crops in the United States. Available at http://www.ers.usda.gov/publications/eib11/ eib11.pdf. USDA-ERS, Washington, D.C.

Fernandez-Cornejo, J., and J. Li. 2005. The impacts of adopting genetically engineered crops in the USA: The case of Bt corn. 2005 Annual Meeting of American Agricultural Economics Association. Providence, RI.

Ferrell, J.A., and W.W. Witt. 2002. Comparison of glyphosate with other herbicides for weed control in corn (Zea mays): Efficacy and economics. Weed Technol. 16:701-706.

Folmer, J.D., R.J. Grant, C.T. Milton, and J. Beck. 2002. Utilization of Bt corn residues by grazing beef steers and $\mathrm{Bt}$ corn silage and grain by growing beef cattle and lactating dairy cows. J. Anim. Sci. 80:1352-1361.

Gomez-Barbero, M., J. Berel, and E. Rodriguez-Cerezo. 2008a. Bt corn in Spain-the performance of the EU's first GM crop. Nature Biotechnology. 26:384-386.

Gomez-Barbero, M., J. Berel, and E. Rodriguez-Cerezo. 2008b. 
Adoption and performance of the first GM crop introduced in EU agriculture: $\mathrm{Bt}$ maize in Spain. Available at http://ftp.jrc.es/EURdoc/JRC37046.pdf.

Gurian-Sherman, D. 2009. Failure to yield: Evaluating the performance of genetically engineered crops. Union of Concerned Scientists. Cambridge, MA.

Heatherly, L.G., C.D. Elmore, and S.R. Spurlock. 2002. Weed management systems for conventional and glyphosate-resistant soybean with and without irrigation. Agron. J. 94:1419-1428.

Heatherly, L.G., K.N. Reddy, and S.R. Spurlock. 2005. Weed management in glyphosate-resistant and non-glyphosate-resistant soybean grown continuously and rotation. Agron. J. 97:568-577.

Heatherly, L.G., S.R. Spurlock, and K.N. Reddy. 2003. Influence of early-season nitrogen and weed management on irrigated and nonirrigated glyphosate-resistant susceptible soybean. Agron. J. 95:446-453.

Holland, J.M. 2004. The environmental consequences of adoption conservation tillage in Europe: reviewing the evidence. Agr. Ecosyst. Environ. 103:1-25.

James, C. 2012. Global Status of Commercialized Biotech/GM Crops: 2011. ISAAA Brief No. 43. ISAAA: Ithaca, NY.

Kapusta G., and R.F., Krausz. 1993. Weed control and yield are equal in conventional, reduced, and no-tillage soybean (Glycine max) after 11 years. Weed Technol. 7: 443-451.

Lauer, J., and J. Wedberg. 1999. Grain yield of initial Bt corn hybrid introductions to Farmers in the Northern corn belt. J. Prod. Agric. 12:373-376.

Locke, M.A., R.M. Zablotowicz, and K.N. Reddy. 2008. Integrating soil conservation practices and glyphosate-resistant crops: Impacts on soil. Pest Manag. Sci. 64:457-469.

Loecker, J.L., N.O. Nelson, W.B. Gordon, L.D. Maddux, K.A. Janssen, and W.T. Schapaugh. 2010. Manganese response in conventional and glyphosate resistant soybean. Agron. J. 102:606-611.

Ma, B.L., F. Meloche, and L. Wei. 2009. Agronomic assessment of Bt trait and seed or soil applied insecticides on the control of corn rootworm and yield. Field Crop. Res. 113:189-196.

Ma, B.L., and K.D. Subedi. 2005. Development, yield, grain moisture and nitrogen uptake of Bt corn hybrids and their conventional near-isolines. Field Crop. Res. 93:199-211.

Macrae, T.C., M.E. Baur, D.J. Boethel, B.J. Fitzpatrick, A. Gao, J.C. Gamundi, L.A. Harrison, V.T. Kabuye, R.M. McPherson, J.A. Miklos, M.S. Paradise, A.S. Toedebusch, and A. Viegas. 2005. Laboratory and field evaluations of transgenic soybean exhibiting high-dose expression of a synthetic Bacillus thuringiensis cry1A gene for control of Lepidoptera. J. Econ. Entomol. 98:577-587.

Magg, T., A.E. Melchinger, D. Klein, and M. Bohn. 2001. Comparison of Bt maize hybrids with their non-transgenic counterparts and commercial varieties for resistance to European corn borer and for agronomic traits. Plant Breeding. 120:397-403.

Marra, M., P. Pardey, and J. Alston. 2002. The payoffs to transgenic field crops: An assessment of the evidence.
AgBioForum. 5:43-50.

McPherson, R.M., and T.C. Macrae. 2009. Evaluation of transgenic soybean exhibiting high expression of a synthetic bacillus thuringiensis cry1A transgene for suppressing lepidopteran population densities and crop injury. J. Econ. Entomol. 102:1640-1648.

Mensah, E.C. 2007. Factors that affect the adoption of Roundup Ready soybean technology in the U.S. J. Econ. Devel. Busin. Polic. 1:90-121.

Mungai, N.W., and P.P. Motavalli, K.A. Nelson, and R.J. Kremer. 2005. Differences in yields, residue composition and $\mathrm{N}$ mineralization dynamics of $\mathrm{Bt}$ and non-Bt maize. Nutr. Cycl. Agroecosys. 73:101-109.

Nelson, K.A., and K.A. Renner. 2001. Soybean growth and development as affected by glyphosate and postemergence herbicide tank mixtures. Agron. J. 93: 428-434.

Oplinger, E.S., M.J. Martinka, and K.A. Schmitz. 1998. Performance of transgenic soybeans: Northern United States. p.10-14. In Proc. 28th Soybean Seed Research Conf. Chicago, IL. American Seed Trade Association, Washington, D.C.

Pilcher, C.D., and M. E. Rice. 2003. Economic analysis of planting dates to manage European corn borer (Lepidoptera: Crambidae) with Bt corn. J. Econ. Entomol. 96:941-949.

Raymer, P.L., and T.L. Grey. 2003. Challenges in comparing transgenic and nontransgenic soybean cultivars. Crop Sci. 43:1584-1589.

Shaw, D.R., J.C. Arnold, C.E. Snipes, D.H. Laughlin, and J.A. Mills. 2001. Comparing of glyphosate-resistant and nontransgenic soybean (Glycine max) herbicide systems. Weed Technol. 15:676-685.

Sheridan, C. 2009. Report claims no yield advantage for Bt crops. Nat. Biotechnol. 27:588-589.

Singer, J.W., J.R. Heckman, J. Ingerson-Maha, and M.L. Westendorf. 2000. Hybrid and nitrogen source affect yield and European corn borer damage. J. Sustain. Agr. 16:4-14.

Singer, J.W., R.W. Taylor, and W.J. Bamka. 2003. Corn yield response of $\mathrm{Bt}$ and near-isolines to plant density. Online, Crop Management doi:10.1094/CM-2003-0829-01-RS.

Stanger, T.F., and J.G. Lauer. 2006. Optimum plant population of Bt and non-Bt corn in Wisconsin. Agron. J.98:914-921.

Subedi, K.D., and B.L. Ma. 2007. Dry matter and nitrogen partitioning patterns in $\mathrm{Bt}$ and non-Bt near-isoline maize hybrids. Crop Sci. 47:1186-1192.

Thomas, W.E., W.J. Everman, J. Allen, J. Collins, and J.W. Wilcut. 2007. Economic assessment of weed management systems in glufosinate-resistant, glyphosate-resistant, imidazolinone-tolerant, and nontransgenic corn. Weed Technol. 21:191-198.

Traore, S.B., R.E. Carlson, C.D. Pilcher, and M.E. Rice. 2000. $\mathrm{Bt}$ and non-Bt maize growth and development as affected by temperature and drought stress. Agron. J. 92:1027-1035.

Triplett Jr., G.B., and W.A. Dick. 2008. No-Tillage crop production: A revolution in agriculture. Agron. J. 100:S-153-S-165.

United Nations (UN). 2012. World Population Prospects: The 2011 Revision Population Database. Available at http://esa.un.org/unpp/. UN, New York, NY. 